Universitas, Volumen 1, Año 1, 2007, 7-13

(C) 2007 UNAN-León, Editorial Universitaria

\title{
Diagnóstico de la calidad del agua de consumo en las comunidades del sector rural noreste del municipio de León, Nicaragua
}

\author{
Oscar González², Javier Aguirre², Gema Saugar ${ }^{1}$, Lyli Orozco ${ }^{1}$, Guadalupe Álvarez', Karen Palacios ${ }^{1}$, Octavio \\ Guevara ${ }^{1 *}$ \\ 1. Laboratorio de Microbiología de Agua, Departamento de Biología, Facultad de Ciencias ; Universidad Nacional Autónoma \\ de Nicaragua, León (UNAN-León). \\ 2. Vicerrectoria de Investigación y Postgrado, Universidad Nacional Autónoma de Nicaragua, León (UNAN-León).
}

\section{RESUMEN}

Es ampliamente conocido que una de las principales fuentes de agua de consumo humano, es el agua subterránea que actualmente está siendo receptora de la contaminación provocada por el ser humano. El objetivo de este estudio fue caracterizar la calidad del agua de consumo humano del sector rural noreste de León. Se realizaron análisis microbiológicos ( $N=69)$, análisis físico-químicos ( $N=67)$ y análisis de plaguicidas $(\mathrm{N}=48)$. Además, se realizó una encuesta sobre las características de las fuentes de agu (pozos), el uso y tratamientos de sus aguas. Los análisis microbiológicos mostraron que un $95.7 \%$ de los resultados, no cumplen con los requisitos establecidos en las normas CAPRE. Según los estándares del laboratorio de microbiología de la UNAN-León, el $97.1 \%$ de las muestras están contaminadas. El 18.8\% de los pozos presenta contaminación físico-química y el $31.3 \%$ de los pozos presentan contaminación con pesticidas. El principal pesticida encontrado fue el Clorpirifos, seguido por DDT. Las pruebas estadísticas asociaron significativamente $(\varphi=0.580, p<0.05)$ la contaminación microbiana con el tipo de pozo. Existe un grado de asociación significativa entre la contaminación microbiana y la presencia de animales cerca del pozo. Los resultados sugieren que la contaminación se da fundamentalmente por introducción directa de mecates contaminados a los pozos.

Palabras claves: coliformes, pesticidas, nitratos, pozos.

\section{INTRODUCCIÓN}

Es ampliamente conocido que una de las principales fuentes de agua de consumo humano, el agua subterránea, actualmente está siendo receptora de las consecuencias provocadas por las diferentes actividades que lleva a cabo el ser humano haciendo de éste un recurso altamente vulnerable al acceso de la misma.

Las diferentes fuentes de agua pueden ver mermada su calidad por dos tipos de contaminación según su origen: 1) contaminación natural o geoquímica, y 2) contaminación antropogénica (causada por el hombre). Gray (1994), propone los siguientes factores de origen natural sobre los que va a depender la calidad del agua: naturaleza del agua de lluvia que rellena los acuíferos, tipos de aguas subterráneas (edad del agua del acuifero), tipo de suelo y el tipo de roca que forma el acuífero. Como factores antropogénicos de contaminación pueden ser: Usos del suelo cercanos a los acuíferos (agrícola, ganadero, etc.) y la infiltración de aguas residuales.

En 1994 se creo el Comité Coordinador Regional de Instituciones de Agua Potable y Saneamiento de Centroamérica, Panamá y República Dominicana (CAPRE), estos son los autorizados para dictar Normas
Técnicas de control de calidad de productos en materia de Agua Potable y Saneamiento entre los países miembros y afiliados. Estas Normas fueron adoptadas por el Ministerio de Salud de la República de Nicaragua, en octubre de 1994, amparado en lo establecido en las Disposiciones Sanitarias en relación a los sistemas de abastecimiento de agua para el consumo humano. Las Normas CAPRE indican los valores permisibles de las diferentes variables microbiológicas, físico-químicas, pesticidas, metales pesados, etc.

De la calidad del agua de consumo que disponen las poblaciones dependen en gran medida la calidad de vida de las mismas, pues el agua insalubre es uno de los diez factores de riesgo que producen mayor carga de morbilidad en el mundo, según estudios de la OMS.

Dependiendo de la contaminación que se esté dando, varía el tipo de enfermedad: contaminación microbiológica es asociada a enfermedades de tipo infecciosa, mientras que en la contaminación fisicoquímica y por plaguicidas las enfermedades son de tipo crónicas. El objetivo de este trabajo fue caracterizar la calidad de agua de consumo de los pozos de las comunidades del sector noreste de León, al comparar algunos parámetros críticos de calidad según las normas CAPRE. 


\section{METODOLOGÍA}

\section{Área de Estudio}

El estudio se realizó en las comunidades del sector rural noreste del Municipio de León. Las comunidades son: Monte Redondo 1, 2, 3, Los Pocitos-Carvajal, El Tololar, Aguedo Morales, La Peineta, Pintora 1,2, Anexo Pintora 1, Reparto 3 de Julio, Palo de Lapa, El Porvenir y La Morita (Fig. 1).

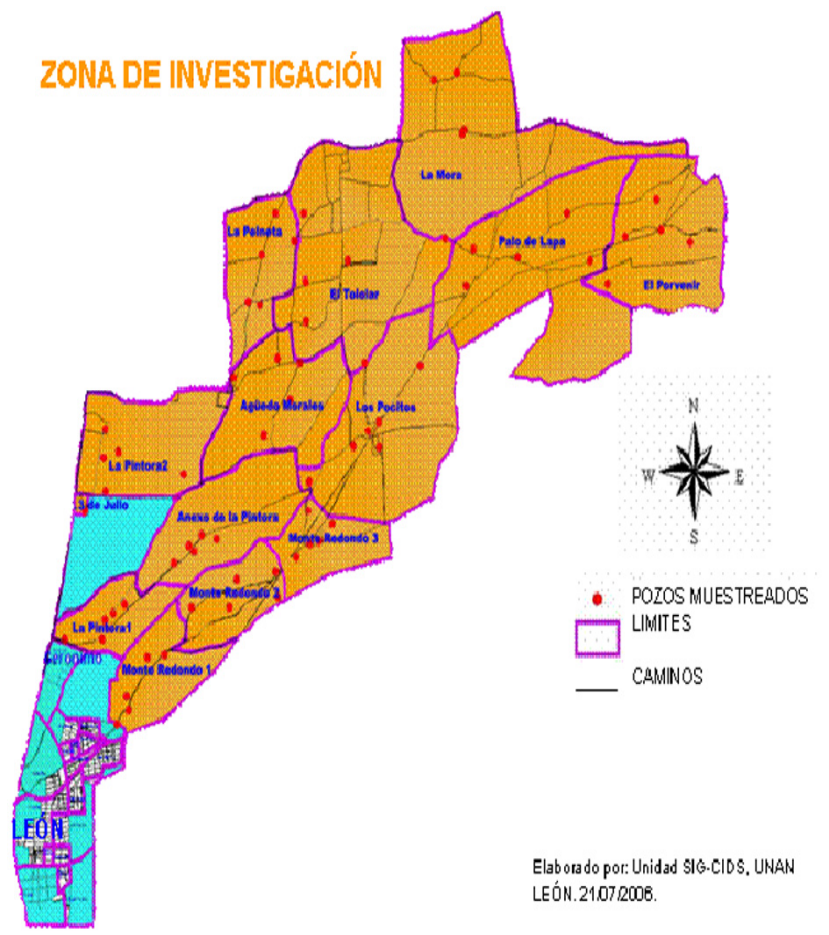

Figura 1. Ubicación de las 14 comunidades del sector noreste de León.

Las 14 comunidades cuentan con una población de 4,918 habitantes. La mayoría de los sectores cuentan con el abastecimiento de agua de pozos privados y comunales. Actualmente se ha gestionado la introducción de Agua Potable con la Agencia Suiza para el Desarrollo y la Cooperación (COSUDE) en los sectores: Monte Redondo, Pintoras, Peineta, Aguedo Morales y El Tololar Central.

El clima de la zona es Tropical de Sabana y su zona de vida según Holdridge es representativa para Bosque Tropical Seco ${ }^{[3]}$. La precipitación total anual promedio presenta muy pocas variaciones, la precipitación promedio oscila entre los 1,150-1,370mm y temperaturas medias anuales que oscilan entre $22-28^{\circ} \mathrm{C}^{[5]}$.

El suelo en el horizonte superficial es de tipo arenoso, y se caracteriza por ser altamente permeables.

\section{DISEÑO DEL MUESTREO}

Los muestreos se realizaron a lo largo de cinco semanas consecutivas de junio-julio del 2006. La selección de los pozos se realizó con los líderes de las 14 comunidades, haciendo uso de mapas elaborados por Defensa Civil, los que reflejaban la ubicación y el número de pozo de cada comunidad. Los pozos se clasificaron en individuales, comunales y tanques de distribución en función de lo que se encontrase en cada comunidad.

\section{Análisis microbiológicos}

Se analizaron 69 fuentes de aguas; 5 por comunidad, muestreadas aleatoriamente. De la selección aleatoria 62 pozos fueron artesanales, 2 pozos perforados y 5 muestras pertenecientes a sistemas de distribución.

Para el análisis bacteriológico, las muestras fueron colectadas en botellas de vidrio estériles de $1000 \mathrm{ml}$. Una vez tomadas la muestras, se conservaron en termos con hielo para brindarle las condiciones óptimas y evitar que los microorganismos mueran, y posteriormente se transportaron al laboratorio en un período de $6 \mathrm{~h}^{[1]}$.

La calidad microbiológica del agua de consumo humano se determino a través de la detección de coliformes totales y fecales, empleando la técnica del Número Más Probable (NMP/100ml) de acuerdo a los métodos de APHA (1989). Este análisis es un requisito básico para el agua de consumo humano de acuerdo a las normas CAPRE. Paralelo a las normas CAPRE se realizó un análisis microbiológico completo, basado en los indicadores de calidad del laboratorio de Microbiología de agua de la Universidad Nacional Autónoma de Nicaragua, León. El análisis incluye la detección cualitativa (presencia o ausencia) de Escherichia coli, Enterococos fecales del grupo Lancefild, Clostridium, Pseudomona, Aerobios mesófilos, Mohos y Levaduras. Todos estos grupos forman parte de la flora microbiana acompañante, que también puede ser factor de riesgo para el padecimiento de ciertas enfermedades por la ingesta de agua contaminada.

\section{Análisis físico-químicos}

Para la realización de los análisis físico-químicos se tomaron 67 muestras de agua en el mismo momento que para los análisis microbiológicos.

Las técnicas de laboratorio empleadas para realizar los diferentes análisis químicos son las siguientes, de acuerdo a Standar Methods for the Examination of Water and Waste Water ${ }^{[1]}$ :

$\mathrm{pH}$ : método potenciométrico.

Conductividad: método conductimétrico.

Sulfato: método turbidimétrico. 
Hierro: método de absorción atómica.

Nitrito: método colorimétrico.

Nitrato: método ultravioleta selectivo.

Dureza total, dureza cálcica, dureza magnética, calcio y magnesio: método compejométrico.

Alcalinidad total, bicarbonato y cloruro: método volumétrico.

\section{Análisis de pesticidas}

Los análisis de pesticidas se realizaron en 48 muestras, 3 por comunidad, a través de extracción en fase sólida con cartuchos $\mathrm{C} 18$, diluidos con acetato de etilo analizados y cuantificados por Cromatografías de Gases con Detector Captura de Electrones (ECD), según MACA-01/Protocolos Agilent, para el análisis de residuos de plaguicidas en aguas por cromatografía de gases con detector ECD. Los análisis se realizaron en el Laboratorio de Análisis de Contaminantes (UNANLeón). El protocolo utilizado se basa en la identificación cualitativa de 11 pesticidas (Tabla 1).

Tabla 1. Pesticidas que se analizan en aguas de consumo humano, por el Laboratorio de Análisis de Contaminantes (UNAN-León)

\begin{tabular}{|c|c|c|}
\hline Análisis & Familia & Regulación \\
\hline Metil-paration & \multirow{4}{*}{ Organofosforados } & $D N D$ \\
\hline Malatión & & $D N D$ \\
\hline Clorpirifos & & $D N D$ \\
\hline Profenofos & & $D N D$ \\
\hline Dieldrin & \multirow{2}{*}{$\begin{array}{l}\text { Organoclorados } \\
\text { persistentes }\end{array}$} & 0.03 \\
\hline$P P D D T$ & & 2 \\
\hline Endosulfán $\alpha$ y $\beta$ & Organoclorados & $D N D$ \\
\hline Cihalotrina & \multirow{4}{*}{ Piretroides } & $D N D$ \\
\hline Permetrina & & $D N D$ \\
\hline Cipermetrina & & $D N D$ \\
\hline Deltametrina & & $D N D$ \\
\hline
\end{tabular}

DND: Datos no disponible en la regulación nacional

\section{Características de los pozos y potenciales fuentes de contaminación}

Se realizó una encuesta al dueño o habitante del lugar donde se encontraba el pozo ( $\mathrm{N}=64$ encuestas). Los principales punto de la encuesta fueron basados en año en que fue construido el pozo, forma de construcción, profundidad, usos generales del agua, tratamiento posterior a su extracción y número de personas que se abastecen. Además, se observó in situ las características de los pozos (existencia de brocal, de fisuras, forma de extraer el agua, etc), ubicación de las letrinas, y charcos. Se elaboraron croquis generales de las viviendas para su posterior análisis.

\section{Análisis de datos}

Para conocer la calidad de agua de cada muestra se compararon los valores obtenidos con los valores permisibles que estipulan las normas CAPRE.

Una vez obtenidos los datos de los diferentes análisis, estos fueron procesados en bases de datos elaboradas en hoja electrónica de cálculo. Se realizaron análisis descriptivos, ANOVA simple, comparaciones múltiples y correlaciones.

\section{RESULTADOS}

\section{Análisis Microbiológicos}

De las 69 muestras analizadas un $95.7 \%$ (63) de los pozos no cumplen con los requisitos establecidos en las normas CAPRE, solamente un $4.3 \%$ (6) se podrían considerar como fuentes que cumplen estos requisitos (Fig. 2).

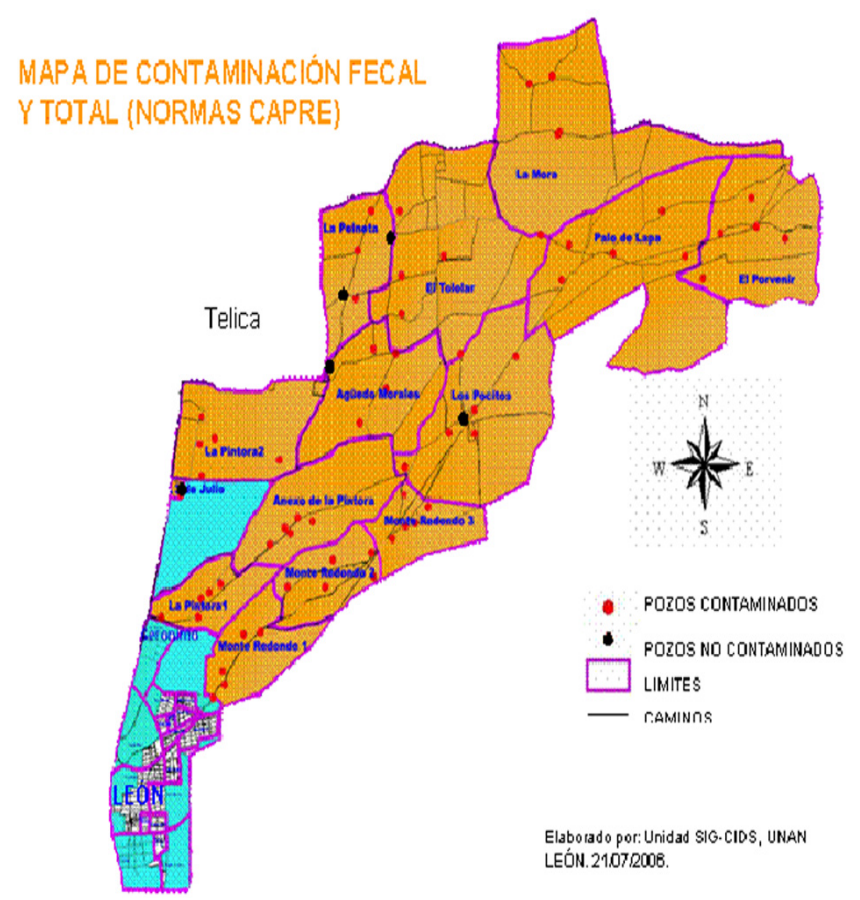

Figura 2. Mapa de distribución de la contaminación microbiológica.

En cuanto al nivel de contaminación de las muestras, la media de Unidades Formadoras de Colonias (UFC) encontradas en las 14 comunidades resultó de 1,685 UFC para coliformes totales (según las normas CAPRE este valor tiene que ser menor o igual a 4 UFC) y de 671 UFC para coliformes fecales (0 UFC según CAPRE) (Tabla 2). 
Tabla 2. Medias de Unidades formadoras de colonias de coliformes totales y fecales en cada comunidad de León noreste.

\begin{tabular}{|c|c|c|}
\hline COMUNIDAD & $\begin{array}{c}\text { Medias de } \\
\text { Coliformes } \\
\text { Totales } \\
\text { (100ml) }\end{array}$ & $\begin{array}{c}\text { Medias de } \\
\text { Coliformes } \\
\text { fecales (100ml) }\end{array}$ \\
\hline Pintora 1 & 1880 & 900 \\
\hline Anexo Pintora & 1300 & 340 \\
\hline 3 de julio & 33.3 & 0 \\
\hline Pintora 2 & 1140 & 400 \\
\hline La Peineta & 1640 & 340 \\
\hline Aguedo Morales & 280 & 140 \\
\hline Tololar & 1380 & 420 \\
\hline La Mora & 960 & 240 \\
\hline Palo de Lapa & 1000 & 400 \\
\hline El Porvenir & 420 & 20 \\
\hline Los Pocitos & 1850 & 316.7 \\
\hline Monte Redondo3 & 5300 & 3300 \\
\hline Monte Redondo 2 & 1920 & 800 \\
\hline Monte Redondo1 & 3440 & 1580 \\
\hline
\end{tabular}

El análisis de ANOVA mostró que existen diferencias significativas $(p<0.05)$ entre las medias de UFC de coliformes fecales y totales en las 14 comunidades. En la figura 10 se puede apreciar que las comunidades que presentaron un mayor número de UFC de Coliformes totales y fecales fueron: Pintora 1, Monte Redondo 1, 2 , y 3 , en un ámbito de 1,880-5,300 UFC para Coliformes totales y $900-3,300$ ufc para Coliformes fecales.

Según la prueba de comparación múltiple de Tukey, se encontraron dos grupos significativos comocomunidades similares con base al grado de contaminación por coliformes totales: a.) Pintora 1 y Monte Redondo 2; b.) Monte Redondo 1 y 3 . En coliformes fecales estableció un solo grupo con valores similares: Monte Redondo 1 y 3 .

\section{Otros parámetros encontrados como indicadores de contaminación de agua.}

Teniendo en cuenta los resultados obtenidos del análisis completo que realiza el Laboratorio de agua de la UNAN-León, se reduce a 2 el número de fuentes de agua que cumplen los requisitos establecidos en las normas CAPRE; la comunidad 3 de Julio (tanque de almacenamiento y red de distribución).

El $68.3 \%$ de las muestras contaminadas tienen presencia de E.coli y el $95.2 \%$ de Enterococus.

Las comunidades que se encontraron con un mayor número de muestras con presencia de estos microorganismos fueron: Monte Redondo 1, 2 y 3, Los Pocitos, Pintora 1 y La Mora.

\section{Parámetros físico químicos}

El $81.2 \%$ de las muestras de agua de los pozos son aptas para consumo humano (basado en las normas CAPRE). El $18.8 \%$ de las muestras presentaron niveles superiores a los máximos permisibles en las normas CAPRE, (Fig. 3). De los diferentes parámetros analizados, el $100 \%$ de las muestras presentaron valores de $\mathrm{pH}$, calcio, hierro, cloruros, sulfatos, alcalinidad total, dureza total y dureza cálcica dentro de los niveles admisibles para cada parámetro. La conductividad presentó valores superiores al máximo permisible (> $400 \mathrm{mS} / \mathrm{cm}$ ) en tres muestras (4.3\%). En la comunidad de Monte Redondo 2 se encontró un pozo con niveles de magnesio superiores al máximo admisible (>50 $\mathrm{mg} / \mathrm{L})$. Así mismo, un pozo de la comunidad de La Peineta presento valores de dureza magnésica altos (>125 mg/L). Las aguas de ambos pozos no cumplen con los indicadores de calidad establecidos por las normas CAPRE. El 92.7\% (64) de las muestras tuvieron una concentración de nitratos por debajo del máximo admisible establecido en las normas CAPRE y un 4.3 $\%$ (tres muestras) presentaron niveles superiores a los admisibles $(<50 \mathrm{mg} / \mathrm{L})$. Las tres muestras pertenecen a las comunidades de La Peineta (152.36 mg/L), Palo de Lapa $(78.06 \mathrm{mg} / \mathrm{L})$ y Monte Redondo 2 (55.36 mg/L). El $10 \%$ de los pozos muestreados presentaron nitritos en cantidades superiores a las permitidas en aguas de consumo humano $(<1 \mathrm{mg} / \mathrm{L})$.

\section{Presencia de Plaguicidas}

De un total de 48 muestras analizadas; el 69\% (33) no se detectó ninguno de los 11 plaguicidas buscados según el método y la técnica de sensibilidad utilizada por el laboratorio. En el 31\% (15) de las muestras se detectó al menos un plaguicida (Fig. 3). El plaguicida más común encontrado fue el Clorpirifos (10), seguido por DDT (3), Metil Paratión (1) y por último el Dieldrin (1). El DDT estaba asociado a la presencia de clorpirifos.

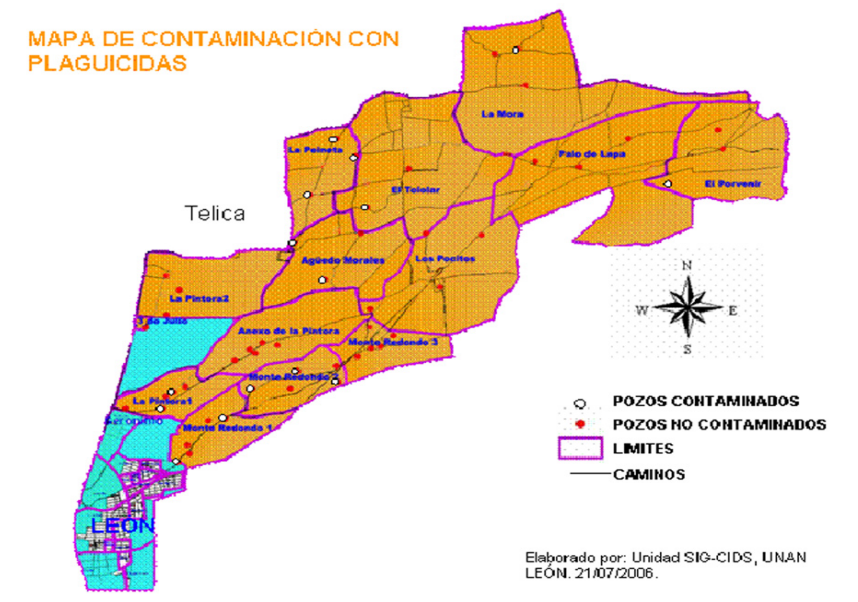

Figura 3. Distribución de la contaminación de plaguicidas en agua de pozos de 14 comunidades de León noreste. 


\section{Estado de los Pozos}

La figura 4 muestra las características estructurales de los pozos (excavados y perforados $n=65$ ), se observa que todos tienen brocales y 57 poseen tapaderas de hierro o de madera, pero sólo un $15 \%$ son pozos sellados.

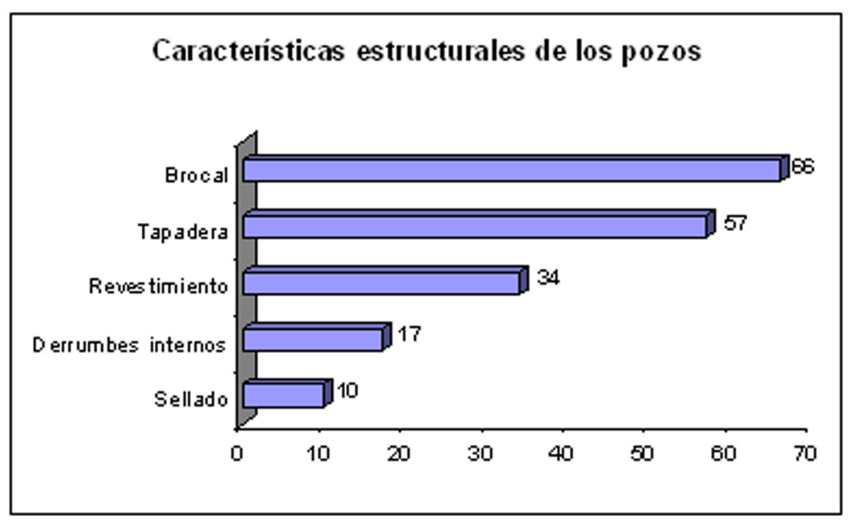

Figura 5. Características estructurales encontradas en la muestra.

La profundidad media de los pozos encontrada en las 14 comunidades fue de 70 varas, siendo las comunidades de El porvenir y Palo de Lapa las que presentan los pozos con mayor profundidad (45-140 vrs). En $89.4 \%$ de los pozos se saca el agua de forma manual (mecates) y $10.6 \%$ con bombas eléctricas.

\section{Localización de los pozos}

El $95.2 \%$ de los pozos se localizan junto a pilas para almacenar agua, baños y lavanderos, es decir zonas que suelen mantenerse encharcadas y facilitar la introducción de contaminantes por medio de filtración. El $70.3 \%$ de las letrinas se encuentran a una distancia mayor o igual a $30 \mathrm{~m}$ del pozo. Aunque la distancia es adecuada, el $29 \%$ de las letrinas están ubicadas en un terreno más alto que el pozo, esto podría ser una posible causa de contaminación. En $63.1 \%$ de los pozos, el ganado llega a tomar agua a la pila próxima al pozo lo que implica que puede haber una elevada concentración de heces en el suelo cercano al pozo. En el $95.5 \%$ de los pozos muestreados el agua es utilizada para todas las actividades de la casa (lavar ropa, regar, aseo personal, consumo, etc). El análisis de asociaciones estableció relaciones altas $(P<0.05)$ entre la contaminación microbiana y las siguientes variables: tipo de pozo, forma de sacar el agua, la profundidad del pozo y la presencia de ganado cercano al pozo.

Con el fin de confirmar la existencia de asociación entre ellas, se realizó un análisis de variables categóricas (de conteo) o prueba estadística $\varphi$, considerando la muestra por el número de individuos, sobre los que se pretende analizar simultáneamente dos atributos o factores (variables cualitativas). Este análisis establece por tanto que los pozos artesanales y sacar agua con mecate está asociado con la presencia de contaminación tanto microbiana como físico-química, el nivel de asociación es alto ( $\varphi=0.551, p<0.05)$. Se observa una asociación ( $\varphi=0.335 ; p<0.05$ ) entre la contaminación microbiana y la presencia de animales consumiendo agua en las pilas cercanas a los pozos.

\section{DISCUSIÓN}

La mayoría de las muestras analizadas microbiológicamente no cumplen los requisitos de acuerdo a las normas CAPRE. Estas normas toman en cuenta la presencia y cuantificación de los Coliformes Fecales y Totales. Los pozos de las comunidades de Monteredondo 1, 2, 3 y Pintora 1 presentaron elevadas cantidades de coliformes fecales y totales. Las personas que consumen o usan el agua de los pozos tienen altas probabilidades de contraer enfermedades causadas por el agua contaminada con Coliformes. Habitualmente suele infravalorarse las consecuencias de la ingesta de agua contaminada microbiológicamente porque suele asociarse a diarreas, enfermedad ampliamente aceptada por su elevado nivel de incidencia.

Las normas CAPRE, están siendo cuestionadas debido a que los niveles de permisividad establecidos se consideran limitados para clasificar los tipos de agua de consumo en apta o no apta, pues no toma en cuenta otros indicadores que pueden enmascarar la presencia de microorganismos que en otros países sí forman parte como indicadores de calidad de agua ${ }^{[2]}$. El análisis de otros indicadores se realiza porque en algunos casos se ha demostrado que la presencia de Coliformes puede ser enmascarada por otros microorganismos patógenos, por ejemplo: Pseudomona aeruginosa, los cuales son resistentes a la cloración ${ }^{[8]}$. Cuando existe crecimiento de esta bacteria los Coliformes Fecales disminuyen su crecimiento debido a que los catabolitos de Pseudomona aeroginosa (piocianina), tienen un efecto bactericida sobre Coliformes, principalmente en $E$. coli, lo cual produciría su disminución o diseminación conduciendo a resultados erróneos en el control de calidad del agua.

En el caso de los enterococos fecales están asociados con enfermedades como gastroenteritis, enfermedades respiratorias, conjuntivitis y dermatitis entre otras. Otra razón es que estos indicadores dan una idea del tiempo en que fue realizada la contaminación del agua y si la contaminación fecal fue de origen animal o humano. Analizando los "otros indicadores microbiológicos", que las normas CAPRE no reflejan, el número de muestras aptas para consumo se reducirían a dos (las dos corresponde a la comunidad 3 de Julio), es decir 
el $97 \%$ de las fuentes de agua no cumplen con los estándares de calidad. En general los valores de los parámetros físico químicos estuvieron por debajo del máximo admisible de acuerdo a las normas CAPRE que rigen a Nicaragua. Se encontraron tres muestras con niveles de conductividad elevada indicando así un alto índice de concentración de solutos. La conductividad es importante también como indicador de posible contaminación con nitratos, ya que existen niveles altos de asociación entre conductividad y nitratos.

Pocas fuentes de agua subterráneas presentaron niveles de nitratos superiores a los establecidos en las normas CAPRE (3 muestras). Sin embargo, no hay que obviar la relevancia del consumo de agua contaminada con este ión para la salud el cual puede ocasionar metahemoglobinemia, una enfermedad mortal para los lactantes ${ }^{[9]}$. Según Gray ${ }^{[2]}$, los nitratos son muy solubles y se disuelven por el agua de lluvia y se infiltran más profundamente en el suelo donde penetran en las aguas subterráneas por infiltración directa o, si encuentran una capa impermeable como arcilla, por migración lateral por el suelo hasta encontrar un camino hasta el agua subterránea.

El $10 \%$ de las familias muestreadas está ingiriendo agua que no cumple los requerimientos CAPRE de nitritos. Los nitritos son indicadores de contaminación fecal a medio-corto plazo, ya que desde que se produce la contaminación hasta que aparecen los nitritos debe pasar un tiempo no excesivamente largo. Aunque, Picone et al. ${ }^{[7]}$, encontró que el contenido de nitritos es variable y no muestra buena correlación con el grado o la antigüedad de la contaminación fecal.

En la comunidad de La Peineta se encontró una muestra en la cual no existía presencia de coliformes fecales y totales (apta microbiológicamente) pero presentó niveles altos de nitratos, conductividad y dureza magnésica (no apta físico-químicamente). Al analizar este caso particular se estimó que esta contaminación puede ser de origen natural pues el pozo fue construido en febrero de este mismo año (cinco meses antes del estudio) y presenta condiciones estructurales adecuadas para evitar la contaminación directa.

El plaguicida encontrado con mayor frecuencia en las muestras de agua fue el Clorpirifos (Lorsban). Este se encuentra asociado a las zonas donde se siembra maní y maíz. El Lorsban es un plaguicida potencialmente muy peligroso, pero no es persistente ${ }^{[2]}$ como el DDT, ya que su persistencia media en el ambiente es de al menos tres meses. La presencia de este plaguicida en el agua indica que se está dando una contaminación cruzada debido a una mala manipulación durante el proceso de extracción de agua. Muchas veces se realiza la preparación de plaguicidas en zonas cercanas a los pozos y se da la introducción de estos plaguicidas a las fuentes de agua a través de la mala manipulación durante el proceso de extracción de agua de los pozos. El Metil-Paration se presentó en una sola muestra, este organoclorado actúa de forma similar que el clorpirifos.

El análisis realizado en el laboratorio de Contaminantes de la UNAN-León no permite discernir que la presencia de DDT sea por contaminación reciente o pasada puesto que para ello habría que analizar la cantidad de metabolitos. Si la concentración de metabolitos de DDT fuera mayor que la de DDT implicaría una contaminación pasada, sin embargo si fuese a lo inverso, nos estaría indicando una contaminación reciente pues no habría pasado el tiempo suficiente para que el DDT se degradase en sus metabolitos residuales.

La presencia de DDT en las fuentes de aguas subterráneas posiblemente ha sido producto de la persistencia que tienen en el ambiente, además del alto grado de infiltración que poseen estos suelos ha provocado que a través del tiempo este plaguicida alcance el manto acuífero por el proceso de percolación, aunque estas fuentes de aguas se encuentran a una profundidad promedio mayor a los $60 \mathrm{~m}$.

Según Gray ${ }^{[2]}$, los organoclorados (DDT y Dieldrin) se consideran los mayores penetrantes por su persistencia, esto es, que se degradan muy lentamente en el ambiente y así continúan actuando durante períodos muy largos de tiempo. Efectivamente, cuando se trata de pozos artesanales (el 95\% de la contaminación microbiológica se da en este tipo de pozos) la forma de extraer el agua es mediante mecates (el 90\% de la contaminación microbiológica se da cuando la extracción del agua es mediante mecate). Mientras que con los pozos perforados o red de distribución la extracción es mediante bomba eléctrica o tubería donde se da un $9.5 \%$ de la contaminación.

Los pozos de estas comunidades no presentaron revestimiento hasta el acuífero y las fisuras de los brocales provocadas por la edad de los mismos era evidente, además la zona es afectada frecuentemente por los sismos causados por la cordillera volcánica. Estas fisuras permiten que la infiltración o lixiviado de microorganismos hacia la parte interior lleguen al acuífero. Según Hornsby ${ }^{[3]}$, los contaminantes del agua subterránea entran al acuífero, esencialmente, a través del agua de recarga de la superficie, con excepción de aquellos casos en que el agua contaminada es inyectada directamente en el acuífero. Si en este caso presumiéramos que la contaminación microbiológica (la más importante en este estudio) fuera debida a la infiltración de los contaminantes por escorrentía subterránea dado que el tipo de suelo es altamente permeable, no debería haberse encontrado 
diferencias significativas entre los diferentes tipos de pozos (perforados o artesanales) puesto que el suelo es arenoso o franco arenoso en todo el sector. Esto no quiere decir que no se esté dando contaminación por infiltración, sino que también se está dando y es relevante la contaminación por introducción directa a la fuente de agua.

El mecate con que se extrae el agua de los pozos, se arrastra en el suelo a una distancia proporcional a la profundidad del pozo. El ganado y las aves de corral depositan sus heces en las cercanías al pozo, por tanto, durante la extracción de agua el arrastre del mecate lleva materia orgánica que se deposita en la fuente de agua. Además pueden existir filtración en la parte inferior del brocal y de esta forma estar entrando contaminación fecal a través de escorrentías facilitado por el tipo de suelo que se encuentra en la zona.

Esta variable ("el ganado toma agua cerca del pozo") ha presentadounaestrechaasociación conlacontaminación microbiológica, la cual desaparece cuando se tiene en cuenta también la calidad físico-química. Este hecho indica que el tipo de contaminación fecal que se está dando en las fuentes de aguas procede de los desechos animales y no del material de las letrinas.

\section{CONCLUSIONES}

En el análisis microbiológico de las aguas de pozos se encontró que el $95.7 \%$ de las muestras analizadas no cumplen los requisitos establecidos según las normas CAPRE. Basándose en los análisis complementarios microbiológicos realizados por el Laboratorio de Microbiología de Agua de la UNAN-León (análisis completo), esta cifra alcanza el $97 \%$. Según el análisis físico-químico el $81.2 \%$ se encontraron dentro de los estándares establecidos en las normas CAPRE.

Las comunidades que presentaron un mayor un número de UFC de Coliformes totales y fecales fueron: Pintora 1, Monte Redondo 1, 2, y 3 . Se encontró la presencia de cuatro pesticidas: DDT, Dieldrin, Clorpirifos y MetilParation en $31 \%(\mathrm{~N}=48)$ de las muestras analizadas. Al ser un análisis cualitativo (presencia o ausencia) las fuentes de agua en las que aparecieron no se pueden calificar como no aptas en función de este factor contaminante.

La principal fuente de contaminación microbiana que se ha encontrado es la inserción de materia fecal a través de los mecates y baldes sucios que se utilizan para la extracción del agua. Los resultados sugieren que la contaminación se da fundamentalmente por introducción directa de mecates contaminados a los pozos.

\section{AGRADECIMIENTO}

Agradecemos a la ONG's Ecología y Desarrollo (ECODES), por el financiamiento para la realización de esta investigación. A las 14 comunidades que nos permitieron realizar esta investigación, en especial a los líderes de cada comunidad. Por último y no menos importante, a los estudiantes de la carrera de Biología (UNAN-León) que participaron en la recolecta de muestras.

\section{BIBLIOGRAFÍA}

1.AMERICAN PUBLIC HEALTHASSOCIATION (APHA). (1989). Standard Methods for the Examination of Water and Wastewater, American Water Works Association \& Water Pollution Control Federation. 17 th ed., WaashintonWashington, D.C.USA. Parte 9000 .

2. Gray, N.F. (1994). Calidad del agua potable problemas y soluciones. Trad. I.E. López. Editorial Acribia, S.A. Zaragoza, España. 365 p.

3.Holdridge, L.R. (1984). ECOLOGY. Segunda Edición. 72 p. Hornsby, A.G. 2000. Agua subterránea: el recurso oculto. Trad. J. Rosales; C. Balerdi y R. Regalado (en línea). Universidad de Florida. Consultado 18 may. 2006. Disponible en http://edis.ifas.ufl.edu/SS313

4.Hunter, C.; J. Perkins, J. Tranter y P. Hardwick. (2000). Fecal bacteria in the water of upland area in Derbishere, England: The influence of agriculture land use. J. Environ. Qual. 29: 1253-1261.

5.Instituto Nicaragüense de Estudios Territoriales (INETER). 2006. Caracterización geográfica del territorio nacional. Precipitación y régimen térmico. Consultado el 11 de abril del 2007. Disponible en: http://www.ineter.gob.ni/caracterizaciongeografica/ capitulo7.2.html

7.Picone, L.I., Y.E, Andreoli, J.L. Costa, V. Aparicio, L. Crespo, J. Nannini, W. Tambascio. (2003). Evaluación de nitratos y bacterias coliformes en pozos de la cuenca alta del Arroyo Pantanoso (BS. AS). INTA. RIA, 32 (1): 99-110.

8.Reilly, K. y J. Kippin. (2000). Relación entre el contaje bacteriológico y otros parámetros de calidad de agua tratada en sistemas de distribución. Hoja de divulgación técnica, CEPIS. $4 \mathrm{p}$.

9.Spalding, R.F., M.E. Exner. (1993). Occurrence of nitrate in groundwater. A review: J. Environ. Qual. 22: 392-402. 